\title{
Understanding hypertext cognition: Developing mental models to aid users' comprehension
}

\author{
Andy White
}

\begin{abstract}
This paper uses literature on hypertext theory to evaluate our reading strategies in an online environment. Assessing the impact of digital technology on our educational environment and culture, the paper recommends a new form of pedagogy for hypertexts based on Walter Ong's concept of 'secondary orality'.

Contents

1. Introduction

2. Hypertext and critical literary theory

3. The materiality of digital media

4. What pedagogical strategies will be used in the new digital environment?

5. Conclusion
\end{abstract}

\section{Introduction}

The major difference between the codex book and digital media is in their respective narrative forms. Cultural theorists have argued that the non-linearity of digital media enables users to engage with the media in the kind of associative way that the human mind works. This article will explore the credibility of these claims and speculate whether the flexibility of non-linear digital media is better able to promote cognition.

Critical literary theory and experiential evidence will be employed to test these claims and to attempt to explain the precise nature and structure of hypertext. In a period where Google, MSN and Yahoo have drawn up plans to create massive digital libraries of English-language books this kind of disquisition will hopefully enable us to form a better understanding of the ways in which these moves will impact on reading and pedagogy.

\section{Hypertext and critical literary theory}

\section{Early 1990s hypertext theory}

Unlike many other computing applications, the design of hypertext is grounded as much in cognitive science, literary theory, pedagogy, utopian social thought, and written and visual arts, as it is in technical developments in computing (Joyce, 1995). Indeed, the pioneer of what is generally regarded as the first, somewhat crude idea of hypertext, Vannevar Bush (1945), conceived of a mechanical contraption — which he termed a 'memex' — that would enable people to search for microfilm records in the 'associative' way that he believed mirrored human cognition [1].

The idea that hypertext represented thought processes was shared by those who followed in Bush's footsteps. Thus, in the 1960s, Engelbart developed a prototype hypertext system that was designed to 'augment' the human mind, while Ted Nelson believed that mind was a 'docuverse' of interconnected documents. In the 1990s Bolter conceived hypertext as a network of symbols, similar to the networks that hypertext produces [2].

Similarly, early 1990s hypertext theorists located their ideas within the perceived 'associativeness' that the media promoted. George Landow used a number of critical literary theorists to promote his belief that hypertext enables people to develop their knowledge in a non-linear, non-sequential, associative way that traditional linear texts do not. 
Drawing largely on Roland Barthes and Jacques Derrida, Landow argues that hypertext is the material embodiment of the textual openness championed by literary theorists decades earlier. This is a theme also taken up by Peter Lunenfeld [3]:

They [digital environments] also seem to offer a privileged place to explore theorist Roland Barthes's valorization of "writerly" textuality, wherein the reader does not encounter a work whose meaning is fixed, but rather (re)writes the text through the process of reading. The "writerly" as opposed to the "readerly" qualities of classical fiction, wherein the art object is static and the hierarchy of creator and consumer is rigidly maintained.

Barthes argued that traditional texts were 'readerly', in the sense that the reader had an essentially passive role. To him, this was not satisfactory as the reader should have a more active role; texts should be 'writerly' [4]:

... the goal of literary work (of literature as work) [which] is to make the reader no longer a consumer, but a producer of the text. Our literature is characterized by the pitiless divorce which the literary institution maintains between the producer of the text and its user, between its owner and its consumer, between its author and its reader. This reader is thereby plunged into a kind of idleness - he is intransitive; he is, in short, serious: instead of functioning himself, instead of gaining access to the magic of the signifier, to the pleasure of writing, he is left with no more than the poor freedom either to accept or reject the text: reading is nothing more than a referendum. Opposite the writerly text, then, is its countervalue, its negative, reactive value: what can be read, but not written: the readerly. We call any readerly text a classic text.

Jacques Derrida was also critical of traditional texts for their lack of openness. He rejected textual uniqueness, arguing for an inter-textuality that deconstructed the binary opposition of 'inside' (in) and 'outside' (of) individual texts. Landow went on to outline Derrida's description of text as a multiplicity of separate units bounded by linguistic markers like commas, speech marks and other forms of punctuation. In doing so, Landow (1992) argued that, like Barthes, Derrida conceived of a literary form that is very similar to hypertext.

These characteristics of hypertextuality are significant in three ways. Firstly, it is argued that inter-textuality is easier to achieve in an environment where hyperlinks allow you to move almost instantaneously from one text to another (or even part of a text to part of another).

Secondly, Barthes's call for a more 'writerly' form of text is pertinent in an environment where authorship is not only sometimes harder to identify, but also philosophically problematic when the reader is essentially the author of his/her own path through hyperspace. Thirdly, the centre of this network of texts is impossible to locate, as it is based on the individual's conception of it [5]:

All hypertext systems permit the individual reader to choose his or her own center of investigation and experience. What this principle means in practice is that the reader is not locked into any kind of particular organization or hierarchy.

These three factors are said to successfully move pedagogy away from linearity and towards the associative form that more accurately reflects cognition.

\section{To what extent does hypertext reflect human cognition?}

There are two criticisms of the aforementioned hypertext theorists, one based on their claims on the nature of reading and the other on their belief in the 'associativeness' of cognition. 
Interestingly, one of the early 1990s theorists, Jay David Bolter, cautioned against some of the totalising claims of the champions of hypertexts [6]:

If poststructuralist theories, and in particular deconstruction, seem to resonate with hypertext, it is important to remember that these theories developed among writers who were primarily working in and with earlier technologies. Deconstruction, for example, worked by reversal, by upsetting tradition, and perhaps the key tradition that it sought to upset was that of humanism in the age of print. To deconstruct a text, one used a vocabulary appropriate to the computer precisely because this vocabulary contradicted the assumptions of print. ... Deconstruction and the other poststructuralist techniques, such as those of Barthes and the reader-response critics, aimed to refashion techniques associated with the printed book from within the technology.

Here, Bolter has argued that reading in the kind of hypertextual way seemingly valorized by both theorists can be achieved within the traditional print-based culture. It is hard to argue that our existing reading practices are strictly linear. Even if we do not always use indices or read individual chapters and passages rather than entire monographs, when we are reading we are constantly aware of the wider canon, an awareness that continually shapes and re-shapes our engagement with the text. In this sense, it is not even clear that Barthes or Derrida were calling for a fundamental alteration in the practice of writing, but perhaps were more concerned with changing the dynamics of the engagement between reader and text.

Further, Dillon argued that there was no evidence in the field of cognitive psychology to support the contention that hypertext reflects the perceived 'associative' working of the human mind (Dillon, 1996). And even if the speculative approach is taken at face value, it is not clear how hypertext would be able to precisely match the 'associativeness' of the brain: "... no conceivable hypertext could be built that would accommodate individual differences in patterns of association" (Miall, 1999). While the debate over 'associativeness' will remain at the level of speculation, studies of reading patterns can enable us to understand the way in which users engage with hypertext.

\section{Empirical studies of hypertext reading strategies}

David Miall, Teresa Dobson and Alex Soojung-Kim Pang are writers who have had practical experience in designing scholarly resources in an electronic format, but are sceptical about many of the claims of hypertext theorists.

\section{In many cultures, reading is both a public and oral practice.}

Pang (1998) illustrated the ways in which, far from being a solitary, passive activity, reading is often an interactive, collective endeavour. In many cultures, reading is both a public and oral practice. Forums such as book groups and even reading in cafés (Pang uses the example of the cluster of cafés surrounding the University of California's Berkeley campus) all encourage a form of collective and interactive reading.

Citing Davida Charney (1994), Miall and Dobson (2001) pointed out that readers can become easily disoriented when navigating hypertext, not only making it difficult for them to locate material, but also placing a disproportionate burden on the efficiency of their short-term memories, and undermining some of their traditional knowledge of concepts like narrative and genre.

Empirical studies of reading strategies in hypertext reinforce this view. Rouet and Levonen (1996) used a number of studies to highlight the tendency of users of hypertext to alight on the same page several times ('looping'), to skim through text rather than read it thoroughly 
('flipping') and to not approach the textual units in any systematic way ('jumping' from unit to unit randomly).

There is a danger that the strength of hypertext - namely the capacity to deliver massive amounts of information to the user - is also its greatest weakness. For Frederic Jameson, the very 'decenterability' that is celebrated by hypertext theorists causes disorientation not just in hyperspace but in modern culture [7]:

[T]his latest mutation in space - postmodern hyperspace — has finally succeeded in transcending the capacities of the individual human body to locate itself, to organize its immediate surroundings perceptually, and cognitively to map its position in a mappable external world. ... [T] his alarming disjunction point between the body and its built environment ... can stand itself as the symbol and analogue of that even sharper dilemma which is the incapacity of our minds, at least in present, to map the great global multinational and decentered communicational network in which we find ourselves caught as individual subjects.

The freedom that many theorists believe that hypertext delivers to its users thus can have profoundly negative consequences for pedagogy.

The importance of comprehension in the reading experience: a return to orality?

In his 1982 book Orality and literacy, Walter J. Ong identifies orality and literacy as representing two distinct modes of thinking. In short, predominantly oral cultures are heavily dependent on nmenonics; language construction is based on the need to promote recall and thus tends to be situational and contextual rather than abstract, aggregative rather than analytic and close to the subject rather than distanced from it.

Dependent as they are written documents that can be referred to in perpetuity, literate cultures do not require formulaic devices to aid memory and tend to be more introspective and selfreflective, but with a less expressive style shaped by their sense of detachment from their readers. Ong argued that the development of the printing industry made literature even more self-contained, producing myriad identical copies of the same work, as well as codifying language with dictionaries and indexes.

Though writing long before the Internet was popularized, Ong foresaw the potential of computer-based text to usher in what he termed the age of 'secondary orality'. In The electronic word: Democracy, technology, and the arts, Richard Lanham (1993), also argued that electronic writing — by this stage making its appearance in the nascent World Wide Web — signified a return to an earlier age: "electronic text enfranchises the oral/rhetorical/dramatistic/semiological world in the same way that print did its literate/philosophical/positivist opposite. The oral world returns in a hyperliterate form.” It certainly is the case that the self-containment of printed works cannot be sustained in an online environment. Further, the World Wide Web privileges information-gathering over the development of the type of logical, analytic thinking typified in print cultures.

The use of multimedia can be viewed as evidence of the type of expressiveness that is typified in oral culture; indeed, in an article in 2002 in First Monday, Claire Harrison's description of the importance of aesthetics in an online environment explicitly links 'rhetoric', one of the central planks of Greek oral culture, with designers of Web content, who are "in fierce rhetorical [my emphasis] competition not only to attract users, but also to keep their attention." 
Thuring, et al. [8] argued that in order to comprehend documents fully, readers must be able to construct "a mental model that represents the objects and semantic relations described in a text." Constructing this model requires some sort of conception of the whole, a difficult thing to achieve in the hypertextual environments described by many hypertext theorists.

Thuring, et al. believed that there are two factors essential for the construction of such models: 'coherence' and 'cognitive overhead'. They described the way in which readers develop coherence in their reading of linear texts by linking together units of text: 'local' coherence is developed through understanding the relationship between clauses and sentences; 'global' coherence through the drawing together of large scale connections through the inter-relationship of not only clauses and sentences but also paragraphs and chapters [9].

Cognitive overhead can loosely be described as the same feeling that Jameson's decentered citizen experiences. In terms of navigating hypertext, Conklin [10] has described it as 'the additional effort and concentration necessary to maintain several tasks at the same time'. In other words, there is a limited cognitive capacity and, therefore, the more mental resources expended merely on orienting oneself inside vast digital archives reduces the capacity for literary tasks like comprehension [11].

This model of comprehension is challenged by Ann-Marie Priest, who used Landow's ideas about the multivocality of the text to champion 'disequilibrium' as a form of pedagogy. In her view the textual anarchy that Thuring, et al. lament should be utilized to develop a constructivist form of learning. With this in mind, she reported on the introduction of an online learning module at Central Queensland University that was intended to facilitate an experiental, postmodern form of pedagogy as promoted by Usher and Edwards [12]:

In giving value to the experiental and the learning engaged in as part of everyday life, the claim is being made that ... There is no single ordered view of the world to be imparted, but multiple 'realities' to be constructed through an already interpreted experience.

The module - 'Hypermedia, hypertext, and postmodern knowledge' on the 'Cultural Technologies' course - featured a home page that obscured totally random links - revealed only when the mouse was run over them. Interestingly, Priest did not reveal whether or not students liked this form of pedagogy or whether, indeed, it was effective in developing their analytical skills. She did, though, undermine her own techno-utopianism by conceding that hypertext can never entirely escape from structuration or design (Priest, 2002).

Other experiental evidence seems to suggest that students find counter-productive the disorientation inherent in textual anarchy.

\section{Other experiental evidence seems to suggest that students find counter-productive the disorientation inherent in textual anarchy.}

A similar exercise was carried out at HATII at the University of Glasgow, where the convenors of an undergraduate module, 'Investigating Cyberspace' encouraged their students to write a non-hierarchical hyperfiction [13]:

When discussing the structure of their collaborative piece, the students continually found themselves returning to some form of hierarchy, which they were initially trying to avoid. With further consideration, they realised that a small element of hierarchy is forgivable and often inevitable, so long as that structure does not solely determine the course of the narrative. 
Miall and Dobson conducted a study of reading patterns in two different online formats linear and nonlinear - for Elizabeth Bowen's short story, "The demon lover," They found that 75 percent of hypertext readers had difficulty following the narrative, while only 10 percent of the linear readers had similar complaints. The exercise was replicated with an even shorter story, Sean O'Faolain's “The trout," with roughly the same results:

In keeping with our expectations, the hypertext version also tended to evoke only generalized comments of involvement with the story, rather than the more specific and emotionally engaged comments of the linear readers. The hypertext readers also tended to find the story confusing or incomplete, some feeling that they may have missed clicking the links that would have made the story achieve coherence (Miall and Dobson, 2001).

Despite his liberationist rhetoric, even George Landow's forays into the world of hypertext have not followed the postmodern path his critical literary writing has blazed. His description of his own Intermedia site does not convey the kind of textual anarchy that his own writings valorise [14]:

Experiences with Intermedia reveal that for those who choose to organize a session on the system in terms of authors - moving, say, from Keats to Tennyson - the system represents an old-fashioned, traditional, and in many ways still useful author-centered approach. On the other hand, nothing constrains the reader to work in this manner, and readers who wish to investigate the validity of period generalizations can organize their sessions in terms of such periods by using the Victorian and Romantic overviews as starting or midpoints while yet others can begin with ideological or critical notions, such as feminism or the Victorian novel.

Indeed, research for this article used both online (of chapter one) and printed versions of Landoww's Hypertext: The convergence of contemporary critical theory and technology, both of which were basically linear in structure.

\section{The materiality of digital media}

Paradoxically, hypertext in its totality contains less potential either for benefit or harm than its champions and detractors claim. Any description of Web-based hypertext as totalising in its anarchy and multi-linearity fails to take into account its materiality. Despite the massive amount of archival material on the Web, there is an even larger non-digitised canon. Building digital libraries is extremely costly, time-consuming, labour-intensive and challenging: there are challenges over accuracy of transcription and academic integrity that need to be overcome before they can be successfully completed (White, 2005). At the IS\&T's annual archiving conference in May 2006, the Librarian and Archivist of Canada, Ian E. Wilson, remarked that though his institution's digitisation programme was ambitious, after ten years, it would have digitised only 0.5 percent of its total holdings (Wilson, 2006).

\section{Building digital libraries is extremely costly, time-consuming, labour-intensive and challenging ...}

Even in the unlikely event that a large proportion of the literary canon was available in a hypertext format, then there are still heavily policed virtual boundaries, be they through restricted access as a result of economic or technical factors, or because of intellectual property rights.

The Google Library Project has stalled amid concerns from publishers that both they and authors are not being appropriately compensated for the use of their books (Newton, 2006). Both Mosco (2004) and Galbraith (1994) have written about the tendency of even the most 
seemingly sagacious of commentators to proclaim at various points in history that a new technology and/or new business venture does not conform to traditional economic models, only to be shocked to discover when investors' lose large amounts of money that, in fact, it does. In this sense, the 'dotcom' boom differed little from the seventeenth century tulip craze. Similarly, many people who sincerely believed that Google was more ethical and powerful than other corporations could not believe that it would make a deal with the Chinese government that effectively restricted content to its Chinese users. In light of this, commitments by any of the major digital library initiatives that the digitised texts will be free at the point of access must be treated with scepticism.

Intellectual property rights and libel laws are as important in online media as they are in printed media [15]. As the Google Library Project has found to its cost, the potential for the kind of inter-textuality championed by hypertext theorists is limited by the fact that it is not in the interests either of publishers or authors to blur the boundaries between texts to the extent that authorship becomes problematic; authors and publishers (especially in academia) are locked into a mutually beneficial relationship that neither would want to jeopardise through the promotion of hypertextual anarchy.

\section{What pedagogical strategies will be used in the new digital environment?}

In a speech to the British House of Lords on 20 April 2006 prominent neurobiologist Professor Susan Greenfield raised concerns about the impact of the proliferation of electronic texts on children's educational development. She questioned whether the conceptual frameworks that children were able easily to develop in print culture are as easily developed in a hypertextual environment:

When we of the twentieth century read a book, most usually the author takes you by the hand and you travel from the beginning to the middle to the end in a continuous narrative series of interconnected steps. It may not be a journey with which you agree or that you enjoy, but none the less as you turn the pages one train of thought succeeds the last in a logical fashion.

We can then of course compare one narrative with another. In so doing we start to build up a conceptual framework that enables us to evaluate further journeys, which in turn will influence our individualised framework. One might argue that this is the basis of education as we know it. It is the building up of a personalised conceptual framework, where we can relate incoming information to what we know already. We can place an isolated fact in a context that gives it significance. Traditional education has enabled us, if you like, to turn information into knowledge (Greenfield, 2006).

Futurelab, a U.K.-based independent body that promotes innovative forms of education, also counsels caution at the claim that hypertext alone can transform children's education. It argues that students must construct 'concept maps' or 'semantic networks' in order to provide a context for their various forms of knowledge and to structure their thinking (Wegerif, 2002).

Both Greenfield and Davies (2005) argue that the growth of the Internet has rendered less important the ability to memorise large amounts of information, because, in theory, we should be able to find even the most arcane facts in a matter of seconds. Given that Ong's idea of orality is dependent on efficient powers of recall, does this mean that his 'secondary orality' thesis is irrelevant?

Ong's [16] description of the techniques needed to memorise information in oral cultures is strikingly similar to the strategies employed by the hypertext readers in the experiments cited earlier in this paper. While the Internet is very good at promoting the instant and precise 
recall of even the most esoteric facts, users must use their memories in order to orientate themselves in cyberspace; anyone who has surfed the World Wide Web for more than five minutes will find themselves trying to recall which pages they previously visited and, perhaps more significantly, the hyperlinks that they did not click and which they will endeavour to follow at a later date. The type of memory needed for this exercise is not what Davies and Greenfield have in mind, but more of the non-verbatim conceptual kind that typified mimesis in oral cultures. In short, memory becomes more not less important in this age of secondary orality.

\section{Conclusion}

Neil Postman's book Technopoly (1993) reminded us that technology is not as free from ideology as its most zealous advocates assert. In this sense we should be wary of those who claim that Internet technology alone will transform education in the twenty-first century they are engaged in an explicitly political project. But neither should we embrace Luddism: the Internet can promote knowledge in innovative ways.

The Internet cannot escape the materiality that earlier technologies like the telegraph, radio, television and cable media were unable to elude; the printed book is not going to disappear from our culture in the foreseeable future. This means that the Internet can be used as a tool for promoting knowledge alongside, not as a replacement for, printed works. It must be accepted, though, that it will be used disproportionately by young people who will need, therefore, to develop their own mental models in this secondary orality.

About the author

Andy White is a Research Associate in the Centre for Media Research at Northern Ireland's University of Ulster, Coleraine, Northern Ireland, U.K.

E-mail: andypwhite2002 [at] yahoo [dot] co [dot] uk

\section{Acknowledgements}

I would like to thank Robert Porter, Laura McAtackney, Julie McAtackney, Andrew Hill and Máire Messenger Davies, Helen Jackson, and First Monday's reviewers for reading a draft version of this paper and making positive comments.

\section{Notes}

[1] It should be noted that others have argued that Paul Otlet, through his 1934 work Traité de Documentation, has a better claim to the mantle of 'inventor of hypertext' (Rayward, 1994).

[2] Ibid.

[3] Lunenfeld, 2000, p. 46.

[4] Barthes, 1974, cited in Landow, 1992, pp. 5-6.

[5] Ibid., pp. 11-13.

[6] Bolter, 1991, pp. 181-182.

[7] Jameson, 1991, p. 44, cited in Gaggi, 1997, p. 9.

[8] Thuring, et al., 1995, p. 57.

[9] Ibid., p. 58.

[10] Conklin, 1987, p. 40, cited in Thuring, et al., 1995, p. 59.

[11] Thuring, et al., 1995, p. 59.

[12] Usher and Edwards, 1994, p. 199, cited in Priest, 2002, p. 540.

[13] Sharp, et al., 2003, p. 7.

[14] Landow, 1992, pp. 11-13.

[15] It is not difficult to find reports of the impact of 'material' factors such as national copyright laws on access to the World Wide Web. For instance, U.K. users of Manhattan 
media blog 'Gawker' were barred from access after complaints from Hello! magazine that the Web site had infringed its copyright of photographs of Brad Pitt and Angelina Jolie's baby (Smith, 2006).

[16] Ong, 1982, pp. 57-68.

\section{References}

R. Barthes, 1974. S/Z. Translated by Richard Miller, 1974. New York: Hill and Wang. J.D. Bolter, 1991. Writing space: the computer, hypertext, and the history of writing.

Hillsdale, N.J.: L. Erlbaum Associates.

V. Bush, 1945. "As we may think," Atlantic Monthly, volume 176, number 1, pp. 101-108

D. Charney, 1994. "The effect of hypertext on processes of reading and writing," In: C.L. Selfe and S. Hilligoss (editors). Literacy and computers: The complications of teaching and learning with technology. New York: Modern Language Association, pp. 238-263.

J. Conklin, 1987. "Hypertext: an introduction and survey," IEEE Computer, volume 20, number 9 (September), pp. 17-41.

W. Davies, 2005. Modernising with purpose: A manifesto for a digital Britain. London: Institute for Public Policy Research.

A. Dillon, 1996. "Myths, misconceptions, and an alternative perspective on information usage and the electronic medium," In: J.-F. Rouet, J.J. Levonen, A. Dillon and R.J. Spiro (editors). Hypertext and cognition. Manwah, N.J.: L. Erlbaum Associates, pp. 25-42.

S. Gaggi, 1997. From text to hypertext: Decentering the subject in fiction, film, the visual arts, and electronic media. Philadelphia: University of Pennsylvania Press.

J.K. Galbraith, 1994. A short history of financial euphoria. London: Penguin.

S. Greenfield, 2006. "Proceedings of the [British] House of Lords" (20 April), at:

http://www.publications.parliament.uk/pa/ld199900/ldhansrd/pdvn/lds06/text/60420-

18.htm\#60420-18_spopq0, accessed 16 June 2006.

C. Harrison, 2002. "Hypertext links: Whither thou goest and why," First Monday, volume 7 number 10 (October), at

http://www.firstmonday.org/issues/issue7_10/harrison/, accessed 28 January 2006.

F. Jameson, 1991. Postmodernism, or, The cultural logic of late capitalism. Durham, N.C.:

Duke University Press.

M. Joyce, 1995. Of two minds: Hypertext pedagogy and poetics. Ann Arbor: University of Michigan Press.

G.P. Landow, 1992. Hypertext: The convergence of contemporary critical theory and technology. Baltimore, Md.: John Hopkins University Press, and at

http://www.cyberartsweb.org/cpace/ht/jhup/contents.html, accessed 28 January 2006.

R.A. Lanham, 1993. The electronic word: Democracy, technology, and the arts. Chicago:

University of Chicago Press.

P. Lunenfeld, 2000. Snap to grid: A user's guide to digital arts, media and cultures.

Cambridge, Mass.: MIT Press.

D.S. Miall, 1999. "The resistance of reading: Romantic hypertext and pedagogy,"

Romanticism on the Net, number 16 (November), at

http://users.ox.ac.uk/ scat0385/reading.html, accessed 28 January 2006.

D.S. Miall and T. Dobson, 2001. "Reading hypertext and the experience of literature,"

Journal of Digital Information, volume 2, number 1, article number 46 (13 August), at

http://jodi.ecs.soton.ac.uk/Articles/v02/i01/Miall/, accessed 28 January 2006.

V. Mosco, 2004. The digital sublime: Myth, power, and cyberspace. Cambridge, Mass.: MIT Press.

N. Newton, 2006. "Google's literary land-grab," Guardian Review [London] (4 March), p. 21, and at http://books.guardian.co.uk/comment/story/0,,1722888,00.html, accessed 1 January 2007.

W.J. Ong, 1982. Orality and literacy: The technologizing of the word. London: Methuen.

A. S-K. Pang, 1998. "Hypertext, the next generation: A review and research agenda," First 
Monday, volume 3 number 11 (November), at http://www.firstmonday.org/issues/issue3_11/pang/, accessed 28 January 2006. N. Postman, 1993. Technopoly: The surrender of culture to technology. New York: Vintage Books.

A.-M. Priest, 2002. "A different quality: Hypertext, postmodernism, and disequilibrium," In: A. Goody, J. Herrington, and M. Northcote (editors). Proceedings of the 2002 Annual International Conference of the Higher Education Research and Development Society of Australasia (HERDSA), Perth, Australia (7-10 July), at http://www.ecu.edu.au/conferences/herdsa/main/papers/ref/pdf/Priest.pdf, accessed 1 January 2007.

J.-F. Rouet and J.J. Levonen, 1996. "Studying and learning with hypertext: Empirical studies and their implications,” In: J.-F. Rouet, J.J. Levonen, A. Dillon and R.J. Spiro (editors).

Hypertext and cognition. Manwah, N.J.: L. Erlbaum Associates, pp. 9-23.

W.B. Rayward, 1994. "Visions of Xanadu: Paul Otlet (1868-1944) and hypertext," Journal of the American Society for Information Science, volume 45, pp. 235-250, and at http://people.lis.uiuc.edu/ wrayward/otlet/xanadu.htm, accessed 1 January 2007.

R. Sharp, P. McKinney, and S. Ross, 2003. "Visual text: Concrete poetry, hyperfiction and the future of the narrative form," Glasgow: Humanities Advanced Technology and Information Institute (HATII), at http://www.ed.ac.uk/iash/vkpublication/Sharp_McKinney_Ross.pdf, accessed 1 January 2007.

D. Smith, 2006. "Brangelina baby shuts snooper site," The Observer [London] (11 June), p. 16, and at http://observer.guardian.co.uk/uk_news/story/0,,1794995,00.html, accessed 1 January 2007.

M. Thuring, J. Hanneman, and J.M. Haake, 1995. "Hypermedia and cognition: Designing for comprehension," Communications of the ACM, volume 38, number 8 (August), pp. 57-66.

R. Usher and R. Edwards, 1994. Postmodernism and education. London: Routledge.

R. Wegerif, 2002. Literature review in thinking skills, technology and learning. NESTSA Futurelab series, report 2.

A. White, 2005. "The development of digital resources by library and information professionals and historians: Two case studies from Northern Ireland," Program: electronic library \& information systems, volume 39, number 4 (October), pp. 324-336.

I.E. Wilson, 2006. "The view of archiving from the Library and Archives Canada," keynote address at the Society for Imaging Science and Technology (IS\&T) Archiving Conference, Ottawa (24 May).

Editorial history

Paper received 31 January 2006; revised 18 June 2006; accepted 10 December 2006.

Creative Commons License

This work is licensed under a Creative Commons Attribution-Noncommercial-Share Alike 2.0 UK: England \& Wales License.

Understanding hypertext cognition: Developing mental models to aid users' comprehension by Andy White

First Monday, Volume 12, Number 1 (January 2007),

URL: http://firstmonday.org/issues/issue12_1/white/index.html

First Monday is one of the first openly accessible, peer-reviewed journals on the Internet, solely devoted to the Internet

http://firstmonday.org/ 